Revista Brasileira de Agricultura Irrigada v.14, nº.2, p. 3897 - 3905, 2020

ISSN 1982-7679 (On-line)

Fortaleza, CE, INOVAGRI - http://www.inovagri.org.br

DOI: $10.7127 /$ rbai.v14n101094

Protocolo 1094.20 - 10/06/2019 Aprovado em 19/06/2020

\title{
CARACTERÍSTICAS PRODUTIVAS DE GENÓTIPOS DE MELÃO AMARELO E PELE DE SAPO EM DUAS ÉPOCAS DE PLANTIO NO SUBMÉDIO DO VALE DO SÃO FRANCISCO
}

\author{
Jony Eshi Yuri ${ }^{*}$, Geraldo Milanez de Resende ${ }^{1}$, Nivaldo Duarte Costa ${ }^{1}$
}

\begin{abstract}
RESUMO
O trabalho foi realizado com o objetivo de avaliar o comportamento de genótipos de melão dos tipos Amarelo e Pele de Sapo em duas épocas de plantio. Os experimentos foram realizados em PetrolinaPE entre os meses de setembro e novembro de 2017 (verão) e maio a julho de 2018 (inverno). O delineamento experimental utilizado foi o de blocos casualizados com oito genótipos de melão tipo Amarelo (Eldorado, Xavantes, Louro, Gladial, BRS Anton, Canarian, Araguaia e SF594) com quatro repetições e cinco genótipos do tipo Pele de Sapo (Finura, Medelin, Sancho, BRS Açu e SV5845MP) com seis repetições. No cultivo de verão, para o melão tipo Amarelo, os genótipos Araguaia (77,6 t $\left.\mathrm{ha}^{-1}\right)$ e Canarian $\left(72,6 \mathrm{t} \mathrm{ha}^{-1}\right)$ foram os mais produtivos comercialmente. No inverno destacaram-se os genótipos BRS Anton (56,7 t ha-1), Louro (55,5 t ha-1) e Canarian $\left(54,8 \mathrm{t} \mathrm{ha}^{-1}\right)$. Para o tipo Pele de Sapo no verão em termos de produtividade comercial sobressaíram os genótipos SV5845MP $\left(86,9 \mathrm{t} \mathrm{ha}^{-1}\right)$, BRS Açu (79,7 t ha $\mathrm{tan}^{-1}$, Sancho (75,8 $\left.\mathrm{t} \mathrm{ha}^{-1}\right)$ e Medelin $\left(75,7 \mathrm{t} \mathrm{ha}^{-1}\right)$. Para o inverno não foram constatadas diferenças significativas entre genótipos para produtividade comercial que oscilou entre 50,0 e 57,2 t ha ${ }^{-1}$. Concluiu-se para o melão tipo Amarelo em cultivo de verão que os genótipos Araguaia e Canarian são os mais recomendados, enquanto no inverno além desses, o genótipo Louro. Para o tipo Pele de Sapo, no verão indica-se os genótipos SV5845MP, BRS Açu, Sancho e Medelin. Em cultivo de inverno pelos maiores valores de produtividade comercial alcançada sugere-se os genótipos SV5845MP e BRS Açu, no entanto, podendo ser plantado todos os genótipos avaliados.
\end{abstract}

Palavras-chave: Cucumis melo; competição; plantio; produtividade.

\section{YIED CHARACTERISTICS OF MELON GENOTYPES YELLOW AND PIEL DE SAPO IN TWO GROWING SEASONS AT SUB-MIDDLE SÃO FRANCISCO VALLEY}

\begin{abstract}
The work was carried out with the objective of evaluating the behavior of melon genotypes of the Yellow and Sapo types in two planting seasons. The experiments were carried out in Petrolina-PE between the months of September and November of 2017 (summer) and May to July of 2018 (winter). The experimental design was a randomized block design with eight cultivars of Yellow melon

\footnotetext{
${ }^{1}$ Autor para correspondência Eng. Agrônomo, D.Sc., Embrapa - Centro de Pesquisa Agropecuária do Trópico Semiárido. E-mails: *jony.yuri@embrapa.br; geraldo.milanez@embrapa.br
} 
(Eldorado, Xavantes, Louro, Gladial, BRS Anton, Canarian and Araguaia) with four replicates and five cultivars of the Pele de Sapo type (Finura, Medelin, Sancho, BRS Açu and SV5845MP) with six replicates. In the summer crop, for the yellow melon, the genotypes Araguaia ( $\left.77.6 \mathrm{t} \mathrm{ha}^{-1}\right)$ and Canarian $\left(72.6 \mathrm{t} \mathrm{ha}^{-1}\right)$ were the most commercially productive. In winter, the genotypes BRS Anton (56.7 $\mathrm{t}$ ha ${ }^{1}$ ), Louro (55.5 $\mathrm{t} \mathrm{ha}^{-1}$ ) and Canarian (54.8 $\mathrm{t} \mathrm{ha-1)} \mathrm{stood} \mathrm{out.} \mathrm{For} \mathrm{the} \mathrm{Piel} \mathrm{de} \mathrm{Sapo} \mathrm{in} \mathrm{the} \mathrm{summer} \mathrm{in} \mathrm{terms}$ of yield the SV5845MP genotypes (86.9 $\left.\mathrm{t} \mathrm{ha}^{-1}\right)$, BRS Açu $\left(79.7 \mathrm{tha}^{-1}\right)$, Sancho $\left(75.8 \mathrm{t} \mathrm{ha}^{-1}\right)$ and Medelin $\left(75.7 \mathrm{t} \mathrm{ha}^{-1}\right)$ were showed. For winter, no significant differences were found between genotypes for commercial yield ranging from 50.0 to $57.2 \mathrm{t} \mathrm{ha}^{-1}$. It was concluded for the Yellow melons in summer planting the Araguaia and Canarian genotypes are the most recommended, while in winter in addition, genotype Louro. For the Piel de Sapo, in the summer it was indicated the SV5845MP, BRS Açu, Sancho and Medellin genotypes. In winter cultivation, the highest values of commercial yield reached suggest the genotypes SV5845MP and BRS Açu, however, and all genotypes evaluated could be planted.

Key words: Cucumis melo L.; competition; planting; yield.

\section{INTRODUÇÃO}

O melão (Cucumis melo L.) é uma das frutas mais apreciadas e de grande popularidade no mundo. Nas últimas décadas, o agronegócio envolvendo o melão se expandiu no Brasil, a ponto de ser considerada a fruta mais exportada. De acordo com o IBGE (2019), a área plantada com a cultura no ano de 2017 foi de 23,4 mil ha que proporcionou volume de colheita de 540,3 mil toneladas com produtividade média de $23,1 \mathrm{t} \mathrm{ha}^{-1}$. A região Nordeste respondeu em 2017 por 95,2 \% da produção nacional, sendo os estados do Rio Grande do Norte, Ceará, Bahia e Pernambuco os maiores produtores. Em Pernambuco e na Bahia a produção concentra-se no Vale do Submédio São Francisco (COSTA, 2017).

Existem diferentes tipos de melão, entretanto, no país, o destaque fica por conta do tipo Amarelo, que tem sido o mais produzido e consumido, em função das suas características quanto ao sabor e a capacidade de transporte. Entretanto, vale também destacar o melão do tipo Pele de Sapo, que tem aumentado muito sua produção, especificamente destinado ao mercado europeu (COSTA, 2017).

É uma planta bastante influenciada por condições ambientais, sobretudo temperatura. Nas condições do Submédio do Vale do São Francisco, o inverno (temperaturas mais amenas) ocorre de abril a setembro e o verão (temperaturas mais elevadas) de outubro a março, onde a temperatura média do ar varia de 24,0 a $28,0^{\circ} \mathrm{C}$, com as temperaturas máxima e mínima oscilando entre 29,6 a $34,0{ }^{\circ} \mathrm{C}$ e de 18,2 a $22,1{ }^{\circ} \mathrm{C}$, respectivamente, para as condições de inverno e verão (TEIXEIRA, 2010).

O plantio de uma cultivar ou genótipo em diferentes condições de solo, clima e manejo da cultura exerce total influência no seu desenvolvimento. $\mathrm{O}$ ambiente aliado ao seu componente genético, promovem respostas fisiológicas e morfológicas dependentes das condições locais as quais são submetidas. A escolha da cultivar é de fundamental importância para seu sucesso, devendo-se levar em consideração além de sua produtividade, aspectos de mercado, comercialização, qualidades agronômicas como resistência a pragas, doenças e ao transporte, a conservação pós-colheita e sólidos solúveis, entre outras características desejadas (SILVA et al., 2005; CARMO et al., 2015; DALASTRA et al., 2015; OLIVEIRA et al., 2015).

Sob condições de cultivo no verão produtividades comerciais variáveis são informadas por diferentes autores. As cultivares de melão tipo Pele de Sapo Sancho e Medelín tem se observado produtividades entre 31,5 e 47,7 $\mathrm{tha}^{-1}$, respectivamente, assim como para as cultivares de melão de Amarelo, entre 24,1 e 46,9 $\mathrm{t} \mathrm{ha}^{-1}$ (DALASTRA et al., 2015; PEREIRA et al., 2017).

O presente trabalho teve por objetivo avaliar o comportamento de genótipos de melão dos tipos Amarelo e Pele de Sapo em 
duas épocas de plantio nas condições do Submédio do Vale do são Francisco.

\section{MATERIAL E MÉTODOS}

O experimento foi realizado no Campo Experimental de Bebedouro, da Embrapa Semiárido, em Petrolina-PE (latitude $9^{\circ} 8^{\prime} 8,9^{\prime \prime}$ $\mathrm{S}$, longitude $40^{\circ} 18^{\prime} 33,6^{\prime \prime} \mathrm{O}$, altitude $\left.365,5 \mathrm{~m}\right)$. Os experimentos foram realizados entre os meses de setembro e novembro de 2017 (verão) e maio a julho de 2018 (inverno), em solo classificado como Latossolo Vermelho Amarelo Distróferrico (SANTOS et al., 2006).
A precipitação pluviométrica acumulada, temperaturas máxima, mínima e média e umidade relativa do ar, ocorrida durante a execução do experimento, são apresentados na Tabela 1.

O delineamento experimental utilizado foi o de blocos casualizados com oito genótipos de melão tipo Amarelo (Eldorado, Xavantes, Louro, Gladial, BRS Anton, Canarian, Araguaia e SF594) e cinco genótipos do tipo Pele de Sapo (Finura, Medelin, Sancho, SV5845MP e BRS Açu), com quatro repetições. A parcela foi constituída por uma linha de sete plantas, considerando-se como parcela útil as cinco plantas centrais.

Tabela 1. Valores mensais de precipitação pluviométrica acumulada, temperaturas máxima, mínima e média e umidade relativa do ar média durante a execução dos experimentos em campo entre setembro a novembro (verão/2017) e maio a julho (inverno/2018). Embrapa Semiárido. Petrolina - PE.

\begin{tabular}{cccccc}
\hline \multirow{2}{*}{ Meses } & $\begin{array}{c}\text { Precipitação } \\
(\mathrm{mm})\end{array}$ & \multicolumn{3}{c}{ Temperatura $\left({ }^{\circ} \mathrm{C}\right)$} & \multirow{2}{*}{ Umidade relativa (\%) } \\
\cline { 3 - 5 } & 12 & Máxima & Mínima & Média & \\
\hline Setembro & 0 & 30,7 & 18,5 & 24,1 & 68,7 \\
Outubro & 7 & 34,8 & 21,6 & 27,8 & 65,6 \\
Novembro & - & 36,1 & 23,5 & 29,3 & 57,7 \\
\hline Média & 6,7 & 32,8 & 21,2 & 27,1 & 64,0 \\
\hline Maio & 0,7 & 32,4 & 20,2 & 25,9 & 73,9 \\
Junho & 0,4 & 31,8 & 19,6 & 25,4 & 62,6 \\
Julho & - & 32,3 & 19,4 & 25,0 & 70,3 \\
\hline Média & & & & 25,4 & \\
\hline
\end{tabular}

A área foi previamente preparada por meio de aração e gradagem. Adotou-se o espaçamento entre linhas de $2,0 \mathrm{~m}$ e entre plantas de $0,3 \mathrm{~m}$. A parcela total foi constituída por duas linhas de plantio contendo sete plantas de cada genótipo $(2,1 \mathrm{~m})$, sendo consideradas úteis, as cinco plantas centrais. O comprimento total das linhas de plantio foi de $29,1 \mathrm{~m}$ e 12,9 $\mathrm{m}$, respectivamente, para $\mathrm{o}$ melão tipos Amarelo e Pele de Sapo, sendo instalado, como bordadura, uma linha extra de cada lado das linhas de avaliação.

As mudas foram produzidas em bandejas de isopor contendo 200 células e preenchidas com substrato comercial (Plantimax), sendo a data de semeio o dia 04/09/2017 (verão) e 07/05/2018 (inverno). As mesmas foram conduzidas em casa de vegetação por um período de 10 dias. $\mathrm{O}$ transplantio dos dois tipos de melão foi realizado no dia 14/09/2017 (verão) e 17/05/2018 (inverno).

As adubações dos experimentos com base na análise do solo constaram da aplicação de 500,0 $\mathrm{kg} \mathrm{ha}^{-1}$ do formulado NPK 06-24-12 no plantio. Em adubação de cobertura, foram adicionados 90,0 $\mathrm{kg} \mathrm{ha}^{-1}$ de $\mathrm{N}, 90,0 \mathrm{~kg} \mathrm{ha}^{-1}$ de $\mathrm{K}_{2} \mathrm{O}, 40,0 \mathrm{~kg} \mathrm{ha}^{-1}$ de Ca e $10,0 \mathrm{~kg} \mathrm{ha}^{-1}$ de $\mathrm{Mg}$, via fertirrigação, três vezes por semana, ao longo do ciclo, até 7 antes da colheita.

A cultura foi mantida no limpo através de capinas manuais, quando necessárias. As irrigações foram feitas através do método de gotejamento, com turno diário e lâminas de água em torno de 7 - $8 \mathrm{~mm}$ (inverno) e 9 - 11 $\mathrm{mm}$ (verão), calculada em função da evaporação do tanque classe A. Foram realizados também os tratos fitossanitários comuns à cultura. 
A colheita dos frutos foi iniciada quando estes se apresentaram em estádio adequado de maturação (cor e aspecto da casca e número de dias após plantio). O melão tipo Amarelo foi colhido com 70 e 78 dias após semeadura e o Pele de Sapo com 77 e 85 dias, no inverno e verão, respectivamente.

Foram avaliadas a produtividade total e comercial de frutos (frutos sem defeitos, rachaduras ou danos mecânicos, sendo para o tipo Amarelo frutos com massa fresca igual ou acima de $1,0 \mathrm{~kg}$ e para o tipo Pele de Sapo com massa fresca igual ou acima de $2 \mathrm{~kg}$ ), número de frutos por planta e massa fresca de fruto comercial. Os dados foram submetidos ao teste de normalidade de Shapiro-Wilk e, quando verificada a normalidade $(\mathrm{p}>0,05)$, que indicaram a não necessidade de transformação. Foi realizada a análise de variância conjunta de experimentos (ANOVA) e as médias comparadas pelos testes de $\mathrm{F}(\mathrm{p}<0,05)$. Verificada diferença significativa entre os tratamentos, as médias foram comparadas pelo teste de Scott-Knott ( $\mathrm{p}<0,05)$, utilizando o programa SISVAR 4.0 (FERREIRA, 2011).

\section{RESULTADOS E DISCUSSÃO}

No verão a produtividade total variou de 57,7 a 86,3 $\mathrm{t} \mathrm{ha}^{-1}$ no grupo amarelo destacandose os genótipos Araguaia e BRS Anton com produtividades acima de $80,0 \mathrm{t} \mathrm{ha}^{-1}$, sem diferirem dos genótipos Canarian, SF 594 e Gladial com produtividades acima de $70,0 \mathrm{t} \mathrm{ha}^{-1}$ (Tabela 2). Com valores oscilando entre 57,74 a 69,3 $\mathrm{t} \mathrm{ha}^{-1}$ mostraram menos produtivos os genótipos Eldorado, Xavante e Louro. Quanto à produtividade comercial os genótipos Araguaia $\left(77,6 \mathrm{t} \mathrm{ha}^{-1}\right)$ e Canarian $\left(72,6 \mathrm{t} \quad \mathrm{ha}^{-1}\right)$ foram estatisticamente diferenciados dos demais em termos produtivos (Tabela 2).

Esses resultados foram bem superiores aos de Santos et al. (2011), que em condições de verão no município de Paulista - PB, obtiveram produtividades total e comercial máximas de 43,9 e 42,6 t ha ${ }^{-1}$, respectivamente. Assim como aos obtidos por para a cultivar Gold Mine com produtividade total de 51,6 $\mathrm{t} \mathrm{ha}^{-1}$ e comercial de 46,9 $\mathrm{t} \mathrm{ha}^{-1}$ (PEREIRA et al., 2010).

Tabela 2. Produtividade total e comercial, massa de fruto e número de fruto por planta de melão do tipo Amarelo em cultivo de verão nas condições do Submédio do Vale do São Fancisco. Petrolina PE, 2017.

\begin{tabular}{|c|c|c|c|c|}
\hline \multirow{2}{*}{ Genótipos } & \multicolumn{2}{|c|}{ Produtividade $\left(\mathrm{t} \mathrm{ha}^{-1}\right)$} & \multirow{2}{*}{$\begin{array}{l}\text { Massa de } \\
\text { fruto }(\mathrm{kg})\end{array}$} & \multirow{2}{*}{$\begin{array}{l}\text { Número de } \\
\text { frutos planta }\end{array}$} \\
\hline & Total & Comercial & & \\
\hline Araguaia & $86,3 \mathrm{a}$ & 77,6 a & $1,76 \mathrm{~b}$ & $2,70 \mathrm{a}$ \\
\hline BRS Anton & $80,7 \mathrm{a}$ & $69,9 \mathrm{~b}$ & $1,98 \mathrm{~b}$ & 2,12 a \\
\hline Canarian & 79,4 a & 72,6 a & $1,80 \mathrm{~b}$ & 2,45 a \\
\hline SF594 & 74,8 a & $63,2 \mathrm{~b}$ & $1,54 \mathrm{~b}$ & $2,45 \mathrm{a}$ \\
\hline Gladial & 73,1 a & $66,7 \mathrm{~b}$ & $2,20 \mathrm{a}$ & $1,91 \mathrm{~b}$ \\
\hline Louro & $69,3 \mathrm{~b}$ & $64,7 \mathrm{~b}$ & $2,26 \mathrm{a}$ & $1,70 \mathrm{~b}$ \\
\hline Xavante & $60,7 \mathrm{~b}$ & $52,8 \mathrm{c}$ & $1,70 \mathrm{~b}$ & $1,87 \mathrm{~b}$ \\
\hline Eldorado & $57,7 \mathrm{~b}$ & $52,5 \mathrm{c}$ & $1,95 \mathrm{~b}$ & $1,62 \mathrm{~b}$ \\
\hline $\mathrm{CV}(\%)$ & 10,0 & 9,5 & 11,7 & 13,0 \\
\hline
\end{tabular}

Médias seguidas de mesma letra minúscula em cada coluna não diferem entre si pelo teste de Scott-Knott, a 5\% de probabilidade.

Quanto à massa fresca de fruto, o destaque foram os genótipos Louro $(2,26 \mathrm{~kg}$ fruto $\left.^{-1}\right)$ e Gladial $\left(2,20 \mathrm{~kg}\right.$ fruto $\left.^{-1}\right)$, sendo estatisticamente superior aos demais. Para os materiais que apresentaram as melhores produtividades comerciais, a massa fresca de fruto encontrada foi de $1,76 \mathrm{~kg}$ fruto $^{-1}$
(Araguaia) e 1,80 kg fruto ${ }^{-1}$ (Canarian). Nunes et al. (2004) verificaram variações na massa fresca entre 0,95 (cultivar Amarillo) a $1,98 \mathrm{~kg}$ fruto $^{-1}$ (cultivar Canarian). Com relação à comercialização, verifica-se que no mercado interno, são preferidos os frutos maiores, com peso unitário de $2,0 \mathrm{~kg}$, tolerando-se uma 
variação de 1,0 a $2,2 \mathrm{~kg}$, enquanto o mercado externo prefere frutos menores entre 0,70 a 1,6 kg (FILGUEIRA, 2008; NICK; BOREM, 2019). Em relação ao número de frutos por planta, os genótipos com as maiores produtividades foram os que também apresentaram maiores valores com 2,70 e 2,45 frutos, respectivamente para Araguaia e Canarian, no entanto, sem diferir dos genótipos BRS Anton e SF594 (Tabela 2). Braga et al. (2017) utilizando diferentes coberturas de solo para as cultivares SF $10 / 00$ e tropical encontraram variações entre 1,1 a 1,7 frutos por planta, abaixo dos valores encontrados no presente trabalho.
Resultados similares com relação aos genótipos mais produtivos foram observados para o plantio de inverno. A produtividade total variou de 37,4 a $65,4 \mathrm{t} \mathrm{ha}^{-1}$ destacando-se os genótipos BRS Anton, Canarian e Araguaia com produtividades acima de $60,0 \mathrm{t} \mathrm{ha}^{-1}$ com menor produtividade apresentada pela cultivar Eldorado $\left(37,4 \mathrm{t} \mathrm{ha}^{-1}\right)$ (Tabela 3). Quanto à produtividade comercial os genótipos BRS Anton $\left(56,7 \mathrm{t} \quad \mathrm{ha}^{-1}\right), \quad$ Louro 55,5 $\mathrm{t} \quad \mathrm{ha}^{-1} \mathrm{e}$ Canarian $\left(54,8 \mathrm{t} \mathrm{ha}^{-1}\right)$ foram estatisticamente diferenciados dos demais em termos produtivos, com menor valor obtido pela cultivar eldorado com $34,3 \mathrm{t} \mathrm{ha}^{-1}$.

Tabela 3. Produtividade total e comercial, massa de fruto e número de fruto por planta de melão do tipo Amarelo em cultivo de inverno nas condições do Submédio do Vale do São Fancisco. Petrolina PE, 2018.

\begin{tabular}{|c|c|c|c|c|}
\hline \multirow{2}{*}{ Genótipos } & \multicolumn{2}{|c|}{ Produtividade $\left(\mathrm{t} \mathrm{ha}^{-1}\right)$} & \multirow{2}{*}{$\begin{array}{l}\text { Massa de } \\
\text { fruto }(\mathrm{kg})\end{array}$} & \multirow{2}{*}{$\begin{array}{l}\text { Número de } \\
\text { frutos planta }\end{array}$} \\
\hline & Total & Comercial & & \\
\hline Araguaia & $60,5 \mathrm{a}$ & $51,2 \mathrm{~b}$ & $1,42 \mathrm{~b}$ & $2,17 \mathrm{a}$ \\
\hline BRS Anton & $65,4 \mathrm{a}$ & 56,7 a & $1,77 \mathrm{~b}$ & $1,93 \mathrm{a}$ \\
\hline Canarian & $65,3 \mathrm{a}$ & $54,8 \mathrm{a}$ & $1,46 \mathrm{~b}$ & $1,93 \mathrm{a}$ \\
\hline SF594 & $59,2 \mathrm{~b}$ & $51,7 \mathrm{~b}$ & $1,53 \mathrm{~b}$ & $2,02 \mathrm{a}$ \\
\hline Gladial & $55,5 \mathrm{~b}$ & $47,9 \mathrm{~b}$ & $2,06 \mathrm{a}$ & $1,30 \mathrm{c}$ \\
\hline Louro & $58,7 \mathrm{~b}$ & $55,5 \mathrm{a}$ & $2,20 \mathrm{a}$ & $1,61 \mathrm{~b}$ \\
\hline Xavante & $52,6 \mathrm{~b}$ & $47,2 \mathrm{~b}$ & $1,67 \mathrm{~b}$ & $1,72 \mathrm{~b}$ \\
\hline Eldorado & $37,4 \mathrm{c}$ & $34,3 \mathrm{c}$ & $1,79 \mathrm{~b}$ & $1,15 \mathrm{c}$ \\
\hline $\mathrm{CV}(\%)$ & 7,8 & 7,4 & 12,2 & 11,6 \\
\hline
\end{tabular}

Médias seguidas de mesma letra minúscula em cada coluna não diferem entre si pelo teste de Scott-Knott, a 5\% de probabilidade.

Relata Freitas et al. (2007) que diversos híbridos de melão do tipo Amarelo cultivados atualmente têm mostrado esse comportamento diferenciado em função de variações edafoclimáticas e do manejo da cultura. Resultados inferiores aos obtidos no nesse estudo são informados por diversos autores (PEREIRA et al., 2010; SANTOS et al., 2011, BRAGA et al., 2017; CARMO et al., 2017).

Quanto à massa fresca de fruto, os genótipos Louro $\left(2,26 \mathrm{~kg}\right.$ fruto $\left.^{-1}\right)$ e Gladial $(2,20)$ foram estatisticamente superiores aos demais. Para os materiais que apresentaram as melhores produtividades comerciais, a massa fresca de fruto encontrada foi de $1,77 \mathrm{~kg}_{\text {fruto }}^{-}$ ${ }^{1}$ (BRS Anton), $1,46 \mathrm{~kg}_{\text {fruto }}{ }^{-1}$ (Canarian) e 2,20 $\mathrm{kg}$ fruto $^{-1}$ (Louro). Esses resultados são inferiores aos observados por Nunes et al. (2004) que obtiveram máxima massa fresca para a cultivar Canarian com $1,98 \mathrm{~kg}$ fruto $^{-1}$.

No entanto, no que se refere à comercialização com destino ao mercado interno que prefere frutos maiores com peso unitário de $2,0 \mathrm{~kg}$, tolerando-se uma variação de 1,0 a 2,2 kg todos os genótipos se enquadram perfeitamente nessa exigência, enquanto para o mercado externo que prefere frutos menores entre 0,70 a $1,6 \mathrm{~kg}$, entre os genótipos mais produtivos somente o "BRS Anton" e "Canarian" poderiam ser comercializados (FILGUEIRA, 2008; $\quad$ NICK; BOREM, 2019). Em relação ao número de 
frutos por planta, os genótipos com as maiores produtividades comerciais apresentaram 1,93 frutos (BRS Anton e Canarian) e 1,61 frutos por planta (Louro), no entanto, sem diferir dos genótipos Araguaia (2,17 frutos por planta) e SF594 (2,02 frutos por planta). Braga et al. (2017) utilizando diferentes coberturas de solo para as cultivares SF $10 / 00$ e tropical encontraram variações entre 1,1 a 1,7 frutos por planta. No meloeiro, o número de frutos na planta aliado à sua massa fresca, são características determinantes na produtividade da cultura. Pela análise das características avaliadas no melão do tipo Pele de Sapo em cultivo de verão observou-se que, com exceção do número de frutos por planta, as demais apresentaram efeitos significativos entre os genótipos (Tabela 4). Em termos de produtividade total, os genótipos SV5845MP, BRS Açu, Sancho e Medelin foram estatisticamente superiores, com produtividades variando de 82,0 a $91,8 \mathrm{t} \mathrm{ha}^{-1}$. Resultado semelhante foi observado também na produtividade comercial. Esses mesmos genótipos apresentaram médias variando de 75,7 a 86,9 t ha $^{-1}$ (Tabela 4).

Tabela 4. Produtividade total e comercial, massa de fruto e número de fruto por planta de melão do tipo Pele de Sapo em cultivo de verão nas condições do Submédio do Vale do São Fancisco.

Petrolina - PE, 2017.

\begin{tabular}{lllll}
\hline \multirow{2}{*}{ Genótipos } & \multicolumn{2}{l}{ Produtividade $\left(\mathrm{t} \mathrm{ha}^{-1}\right)$} & $\begin{array}{l}\text { Massa de } \\
\text { fruto }(\mathrm{kg})\end{array}$ & $\begin{array}{l}\text { Número de } \\
\text { frutos/planta }\end{array}$ \\
\cline { 2 - 4 } & Total & Comercial & $3,20 \mathrm{a}$ & $1,62 \mathrm{a}$ \\
SV5845MP & $91,8 \mathrm{a}$ & $86,9 \mathrm{a}$ & $2,68 \mathrm{~b}$ & $1,83 \mathrm{a}$ \\
BRS Açu & $83,1 \mathrm{a}$ & $79,7 \mathrm{a}$ & $2,27 \mathrm{~b}$ & $2,00 \mathrm{a}$ \\
Sancho & $82,8 \mathrm{a}$ & $75,8 \mathrm{a}$ & $2,52 \mathrm{~b}$ & $1,79 \mathrm{a}$ \\
Medelin & $82,0 \mathrm{a}$ & $75,7 \mathrm{a}$ & $2,28 \mathrm{~b}$ & $1,66 \mathrm{a}$ \\
Finura & $68,9 \mathrm{~b}$ & $63,0 \mathrm{~b}$ & 8,8 & 12,3 \\
\hline CV $(\%)$ & 12,1 & 11,3 &
\end{tabular}

Médias seguidas de mesma letra minúscula em cada coluna não diferem entre si pelo teste de Scott-Knott, a 5\% de probabilidade.

O genótipo Finura apresentou nas duas características as menores produtividades com 68,9 e 63,0 tha ${ }^{-1}$, respectivamente. Pereira et al. (2017) observaram produtividades comercial e total inferiores para as cultivares Medellín (41,81 e 50,12 $\mathrm{t} \mathrm{ha}^{-1}$, respectivamente) e Sancho de 38,8 e $47,7 \mathrm{t} \mathrm{ha}^{-1}$, respectivamente. Assim como outros autores observaram produtividades menores as encontradas no presente trabalho (NUNES et al., 2008; MEDEIROS et al., 2011; DALASTRA et al., 2015).

Para a massa fresca de fruto, o destaque foi o genótipo SV5845MP, sendo estatisticamente superior aos demais, com média de $3,20 \mathrm{~kg}$ fruto $^{-1}$. Comparativamente aos resultados do presente trabalho Pereira et al. (2017) observaram valores superiores para as cultivares Medellín (3,01 kg fruto $\left.^{-1}\right) \mathrm{e}$ Sancho $\left(2,90 \mathrm{~kg}\right.$ fruto $\left.^{-1}\right)$, enquanto Carmo et al. (2017) obtiveram para a cultivar Pele de Sapo Juazeiro com 2,07 kg fruto $^{-1}$.
Dalastra et al. (2015) ao contrário encontrou valores bem menores com $1,44 \mathrm{~kg}$ fruto $^{-1}$ para a cultivar Sancho e 1,62 kg fruto ${ }^{-1}$ para a cultivar Medelin. Os valores obtidos são similares e encontram-se dentro da variação para massa fresca de fruto relatada para diferentes linhagens entre 2,21 e 3,44 $\mathrm{kg}^{\text {fruto }}$ 1 relatados por Nunes et al. (2011). Nessa situação, todos os genótipos avaliados podem ser comercializados no mercado europeu, além do mercado nacional.

$\mathrm{O}$ número de frutos por planta não foi afetado significativamente. Os valores encontrados variaram entre 1,62 e 2,00 frutos por planta. Segundo Nunes et al. (2011) nos híbridos atuais, em média, são colhidos 1,5 frutos por planta no padrão comercial. Resultados superiores aos observados por Pereira et al. (2017) para as cultivares Medellín (1,07 frutos por planta) e Sancho (1,11 frutos por planta). Para o cultivo de inverno não foram constatadas diferenças significativas entre os 
genótipos para produtividade total que variou entre 56,9 a $61,1 \mathrm{t} \mathrm{ha}^{-1}$ e comercial com oscilações entre 50,0 a $57,2 \quad \mathrm{t} \quad \mathrm{ha}^{-1}$ (Tabela 5). Esses resultados sãosuperiores aos observados por diferentes autores (NUNES et al., 2008; MEDEIROS et al., 2011; DALASTRA et al., 2015; PEREIRA et al., 2017).

Tabela 5. Produtividade total e comercial, massa de fruto e número de fruto por planta de melão do tipo Pele de Sapo em cultivo de inverno nas condições do Submédio do Vale do São Francisco. Petrolina - PE, 2018.

\begin{tabular}{lllll}
\hline \multirow{2}{*}{ Genótipos } & \multicolumn{2}{l}{ Produtividade $\left(\mathrm{t} \mathrm{ha}^{-1}\right)$} & $\begin{array}{l}\text { Massa de } \\
\text { fruto }(\mathrm{kg})\end{array}$ & $\begin{array}{l}\text { Número de } \\
\text { frutos planta }\end{array}$ \\
\cline { 2 - 5 } & Total & Comercial & $2,75 \mathrm{a}$ & $1,24 \mathrm{~b}$ \\
\hline SV5845MP & $61,1 \mathrm{a}$ & $57,2 \mathrm{a}$ & $1,97 \mathrm{bc}$ & $1,65 \mathrm{a}$ \\
BRS Açu & $59,8 \mathrm{a}$ & $54,5 \mathrm{a}$ & $1,70 \mathrm{c}$ & $1,77 \mathrm{a}$ \\
Sancho & $57,9 \mathrm{a}$ & $50,0 \mathrm{a}$ & $2,04 \mathrm{~b}$ & $1,49 \mathrm{ab}$ \\
Medelin & $56,0 \mathrm{a}$ & $50,7 \mathrm{a}$ & $1,83 \mathrm{bc}$ & $1,65 \mathrm{a}$ \\
Finura & $56,9 \mathrm{a}$ & $50,5 \mathrm{a}$ & 7,0 & 8,2 \\
\hline CV $(\%)$ & 12,1 & 9,7 & &
\end{tabular}

Médias seguidas de mesma letra minúscula em cada coluna não diferem entre si pelo teste de Scott-Knott, a 5\% de probabilidade.

O genótipo SV5845MP destacou significativamente dos demais em termos de massa fresca de fruto com $2,75 \mathrm{~kg}$ fruto $^{-}$ ${ }^{1}$ seguido dos genótipos Medelín (2,04 kg fruto$\left.{ }^{1}\right)$, BRS Açu $\left(1,97 \mathrm{~kg}_{\text {fruto }}{ }^{-1}\right)$ e Finura $(1,83 \mathrm{~kg}$ fruto $^{-1}$ ) que por sua vez não diferenciaram estatisticamente entre si e do genótipo Sancho $\left(1,70 \mathrm{~kg} \mathrm{fruto}^{-1}\right)$.

Segundo Sales Júnior et al. (2006) o melão Pele de Sapo é muito apreciado principalmente no mercado espanhol, sendo comercializados, no Porto de Natal, frutos entre 2,5 e $3,5 \mathrm{~kg}$. Nesse cenário frutos produzidos nessa época somente do genótipo SV5845MP poderiam ser comercializados no mercado europeu, os demais pela aceitação de frutos menores poderiam ser destinados ao mercado nacional.

Com relação ao número de frutos por planta verifica-se que todos os genótipos tiveram um comportamento semelhante com valores para os genótipos Sancho (1,77 frutos por planta), BRS Açu e Finura (1,65 frutos por planta) e Medelín (1,49 frutos por planta) que não mostraram diferenças significativas centre si e do genótipo SV5845MP (1,24 frutos por planta).

Valores inferiores aos observados no presente trabalho são informados por Pereira et al. (2017) para as cultivares Medellín (1,07 frutos por planta) e Sancho (1,11 frutos por planta).

Observando os valores obtidos em termos produtivos para genótipos tipo Amarelo e Pele de Sapo, nas duas épocas de plantio, se verifica um melhor desempenho de todos os genótipos quando cultivados sob condições de verão. A variação média da temperatura do ar no ambiente deve manter-se dentro dos limites críticos da cultura ao longo do seu ciclo, que conforme Angelotti e Costa (2019) situa-se entre 24 a $32^{\circ} \mathrm{C}$, sendo que a condição extrema de temperatura mínima é de $12^{\circ} \mathrm{C}$ e máxima de $35^{\circ} \mathrm{C}$. Valores acima desta faixa ideal favorecem a produção de melões pequenos e de sabor inferior, geralmente com baixo teor de açúcares (OLIVEIRA et al., 2017). Em média na execução do trabalho no cultivo de inverno/verão foram obtidas temperatura média de $25,4^{\circ} \mathrm{C} / 27,1^{\circ} \mathrm{C}$, com mínima em $19,7 / 21,1^{\circ} \mathrm{C}$ e máxima de $32,3 / 33,9^{\circ} \mathrm{C}$, umidade relativa de 70,9/64\% e 7,8/19,0 mm de precipitação acumulada no período (Tabela 2). As temperaturas ocorridas no inverno (temperaturas amenas) foram inferiores às do verão (temperaturas mais levadas) o que favoreceu as melhores produtividades de verão no qual a cultura melhor se adapta, não sendo, no entanto, um fator limitante que inviabilize o cultivo sob estas condições. 


\section{CONCLUSÃO}

Em função dos resultados obtidos para as condições do Submédio do Vale do São Francisco recomenda-se para o melão tipo Amarelo em cultivo de verão os genótipos Araguaia e Canarian. Para cultivo de inverno os genótipos Araguaia, Canarian e Louro.

Para o melão do tipo Pele de Sapo, em cultivo de verão indica-se os genótipos SV5845MP, BRS Açu, Sancho e Medelin. Em cultivo de inverno pelos maiores valores de produtividade comercial alcançada sugere-se os genótipos SV5845MP e BRS Açu, no entanto, podendo ser plantado todos os genótipos avaliados.

\section{REFERÊNCIAS BIBLIOGRÁFICAS}

ANGELOTTI, F.; COSTA, N.D. Clima. In: Sistema de produção de melão Embrapa Semiárido. Versão eletrônica, 2010. Disponível em: <https://sistemasdeproducao.cnptia. embrapa.br/Fontes

HTML/Melao/SistemaProducao>. Acesso em: 11 abr. 2019.

BRAGA, M.B; MAROUELLI, W.A.; RESENDE, G.M.; MOURA, M.S.B.; COSTA, N.D.; CALGARO, M.; CORREIA, J.S. Coberturas do solo e uso de manta agrotêxtil (TNT) no cultivo do meloeiro. Horticultura Brasileira, v. 35, n. 1, p. 147-153. 2017. http://dx.doi.org/10.1590/S010205362017012 3.

CARMO, I.L.G.S.; FERREIRA, R.S.; SOUZA, J.T.A.; FIGUEREDO, L.F. MEDEIROS, R.D. Produção e qualidade de cultivares de melão em Savana de Boa Vista, Roraima. Revista Agropecuária Técnica, Areia-PB, v. 38 , n. 2, p. 78-83, 2017. DOI: 10.25066/agrotec.v38i2.28212

CARMO, I.L.G.S.; SILVA, E.S.; MONETEIRO NETO, J.L.; TRASSATO, L.B.; MEDEIROS, R.D.; PORTO, D.S. Desempenho agronômico de cultivares de melancia no cerrado de Boa Vista, Roraima.
RevistaAgro@mbiente On-line, Boa Vista, v. $9, \quad$ n. 3, p. 268- 274, 2015. http://dx.doi.org/10.18227/19828470ragro.v9i3.2531.

COSTA, N.D. (Ed.) Coleção Plantar: Melão. 3 ed. Brasília: Embrapa, 2017. 191p.

DALASTRA, M.G.; ECHER, M.M.; HACHMANN, T.L. Desempenho de cultivares de melão, em função do número de frutos por planta. Journal Agronomic Sciences, Umuarama, v.4, n.1, p.26-41, 2015.

FERREIRA, D.F. Sisvar: a computer statistical analysis system. Ciência e Agrotecnologia, Lavras, v. 35, n.6, p. 1039-1042, 2011. http://dx.doi.org/10.1590/S141370542011000 600001.

FILGUEIRA, F.A.R. Novo manual de olericultura: agrotecnologia moderna na produção e comercialização de hortaliças. Viçosa: Editora UFV, 3 ed. 2008. 421p.

FREITAS, J.G.; CRISÓSTOMO, J.B; SILVA, F.P.; PITOMBEIRA, J.B.; ALVES, F.J.; TÁVORA, F. Interação entre genótipo e ambiente em híbridos de melão Amarelo no Nordeste do Brasil. Revista Ciência Agronômica, Fortaleza, v.38, n.2, p.176-181, 2007.

IBGE - Instituto Brasileiro de Geografia e Estatística. Produção Agrícola Municipal. Disponível em <www.sidra.ibge.gov.br.> Acesso em: 25 mar. 2019.

MEDEIROS, D.C.; MEDEIROS, J.F.; DIAS, P.M.S.; BARBOSA, M.A.G.; SILVA LIMA, K.S. Produção de melão Pele de Sapo híbrido 'Medellín' cultivado com diferentes salinidades da água. Revista Ciência Agronômica, Fortaleza, v. 42, n. 3, p. 628-634, 2011. http://dx.doi.org/10.1590/S180666902011000300008.

NICK, C.; BOREM, A. Melão do plantio a colheita. Viçosa: Editora UFV, 2019. 246p. 
NUNES, G.H.S.; COSTA FILHO, J.H.; SILVA, D.J.H.; CARNEIRO, P.C.S.; DANTAS, M.S.M. Divergência genética entre linhagens de melão pele de Sapo. Revista Ciência Agronômica, Fortaleza, v. 42, n. 3, p. 765-773, 2011. http://dx.doi.org/10.1590/S180666902011000300024.

NUNES, G.H.S.; PEREIRA, E.W.L.; SALES JUNIOR, R.; BEZERRA NETO, F.; OLIVEIRA, K.C.; MESQUITA, L.X. Produtividade e qualidade de frutos de melão pele-de-sapo em duas densidades de plantio. Horticultura Brasileira, Brasília, v. 26, p. 236-239, 2008. http://dx.doi.org/10.1590/S010205362008000200021.

NUNES, G.H.S.; SANTOS JÚNIOR, J.J.S.; ANDRADE, F.V.; BEZERRA NETO, F.; ALMEIDA, A.H.B.; MEDEIROS, D.C. Aspectos produtivos e de qualidade de híbridos de melão cultivados no agropolo MossoróAssu. Horticultura Brasileira, Brasília, v.22, n.4, p.744-747, 2004. http://dx.doi.org/10.1590/S010205362004000400015.

OLIVEIRA, F. I. C.; NUNES, A. C.; SILVA, F. D.; SILVA, G. T. M. A.; ARAGÃO, F. A. S. A cultura do melão. In: FIGUEIRÊDO, M. C. B.; GONDIM, R. S.; ARAGÃO, F. A. S. (Org.). Produção de melão e mudanças climáticas: sistemas conservacionistas de cultivo para redução das pegadas de carbono e hídrica. Brasília: Embrapa, 2017. 302 p.

OLIVEIRA, J.B.; GRANGEIRO, L.C.; ESPINDOLA SOBRINHO, L.; MOURA, MS.B.; CARVALHO, C.A.C. Rendimento e qualidade de frutos de melancia em diferentes épocas de plantio. Revista Caatinga, Mossoró, v. 28, n. 2, p. 19-25, 2015.

PEREIRA, F.A.L.; MEDEIROS, J.F.; GHEYI, H.R.; DIAS, N.S.; PRESTON, W.; VASCONCELOS, C.B.E.L. Tolerance of melon cultivars to irrigation water salinity. Revista Brasileira de Engenharia Agrícola e Ambiental, Campina Grande, v.21, n.12, p.
846-851, 2017. Http://dx.doi.org/10.1590/18071929/agriambi.v21n12p846-851.

PEREIRA，F.H.L.; PUIATTI，M.; FINGER, F.L.; CECON, P.R.; AQUINO, L.A. Produção e qualidade de frutos de melões amarelo e charentais cultivados em ambientes sombreados. Revista Brasileira de Engenharia Agrícola e Ambiental, Campina Grande, v.14, n. 9, p. 944-950, 2010. http://dx.doi.org/10.1590/S141543662010000 900006

SALES JÚNIOR, R.; ROCHA, J. M. de M.; MENDES, A. M. S.; NUNES, G. H. de S.; NASCIMENTO, M. T.A. Qualidade do melão exportado pelo porto de Natal-RN. Ciência Rural, Santa Maria, v. 36, n. 1, p. 286-289. 2006. http://dx.doi.org/10.1590/S010384782006000100045.

SANTOS, H.G.; JACOMINE, P.K.T.; ANJOS, L.H.C.; OLIVEIRA, V.A.; LUMBRERAS, J.F.; COELHO, M.R.; ALMEIDA, J.A.; ARAÚJO FILHO, J.C.; OLIVEIRA, J.B.; CUNHA, T.J.F. (Eds.) Sistema brasileiro de classificação de solos. 5. ed. Rio de Janeiro: Embrapa Solos, 2018. 356p.

SANTOS, M. F. dos; COSTA, C. C.; OLIVEIRA, E. M. de; BARBOSA, J. W. S. Avaliação de genótipos de melão amarelo em Paulista, PB. Tecnologia e Ciência Agropecuária, João Pessoa, v. 5, n. 1, p. 1-6, 2011.

SILVA, L.A.; INNECCO, R.; COSTA, J.T.A.; MELO, F.I.O.; MALUF, W.R.; PEDROSA, J.F. Estudo de aspectos quantitativos e qualitativos de frutos de genótipos de melão. Revista Ciência Agronômica, Fortaleza, v. 36, n. 3, p. 310-315, 2005.

TEIXEIRA, A.H.C. Informações agrometeorológicas do Pólo Petrolina, PE/Juazeiro - 1963 a 2009. Petrolina: Embrapa Semiárido. 2010. 21p. (Embrapa Semiárido. Documentos, 233). 